\title{
The Narration of Women from the Aspect of History in May-Lee Chai's Works
}

\author{
Lili Guo \\ The School of Foreign Language, Heihe University, Heihe, Heilongjiang Province, China
}

Keywords: Female consciousness; Value transmission; Historical writing.

\begin{abstract}
The Girl Form Purple Mountain is one of the magnum opuses of May-Lee Chai, a Chinese-American female author of $\mathrm{X}$ generation. It is a biographical novel. One of the salient features of May-Lee Chai's novels is the description of female images and the authentic Chinese history. Its value viewpoint contains the pursuit in truth, kindness and beauty. She has always been faithful to write history. This kind of insistence that shows her own value differentiates on the Chinese images and elemental analysis created in the traditional Chinese-American literature. With the introduction of May-Lee Chai and her important works as the foundation, it can be concluded that the Chinese culture and history is the foothold in her novels. Then, the paper mainly points out that the creation of woman images and the research on conscious structure and value transmission would be more meaningful based on the historical context, historical perspective and historical spirit. Consequently, women, as the protagonist of historical narration, have gradually become an approach to understand history and culture. From the aspect of the integrated writing of women and history, the paper studies May-Lee Chai's novels and relevant literature works and analyzes the unique style of May-Lee Chai's novels, which is of great significance in studying the Chinese-American literature in the 1990s.
\end{abstract}

\section{Introduction of the Author and Her Works}

\subsection{May-Lee Chai.}

In a new generation of Chinese American writers, May-Lee Chai has more complex and care to China. She has totally changed the narrative pattern of orientalism style written in most Chinese-American literature. She was born in an intellectual immigrant family. Her grandparents were all American overseas students who graduated from China's famous universities. his father was born in Shanghai and he was a social political scientist specializing in Chinese studies and his mother was an Irish-American. The strong Chinese cultural atmosphere in the family has a great influence on her. In order to better understand China and Chinese culture, she studied Chinese and got a bachelor's degree in Chinese major from Grinnell College and a master's degree in east Asian study major from Yale university. In addition, she followed her grandmother's footsteps to study at Nanjing University and spent two years as a foreign teacher of a middle school in Nanjing. Nowadays, she still travels to China regularly. These special experiences enable her to understand the contemporary Chinese people and understand the real Chinese culture.

\subsection{Works.}

"May-Lee Chai published her first novel My Lucky Face in 1997. She translated The Autobiography of Ba Jin in January 2008, according to Ba Jin's prose work Memory. During these eleven years, she always paid attention to China, and told us a lot of interesting Chinese stories."1 Chai's first novel, My Lucky Face, has well explained the author's literary direction of "anti-orientalism"."This novel is a real Chinese novel. "This novel tells the story about the awakened individual consciousness of a grass-roots Chinese woman in the late 1980s and early 1990s."2 The publication of the novel has attracted the attention of many critics. 
The English version of The Autobiography of Ba Jin translated according to Ba Jin's prose work Memory was published by the University of Indianapolis Press. Memory includes a collection of reminiscence proses written by Ba Jin in the 1930s. Originally it was published under the title of Autobiography of Ba Jin. Then it was printed and published in the name of Memory after the author supplemented and adjusted the content. When Chai published her book, she gave an introduction to English readers: This translation book was first published in English in the United States. It is written by one of the most influential Chinese authors of the last century. "It reflects the author's early life in his well-bred, wealthy family. This makes this autobiography very intriguing after many years of his writing."3

The Girl Form Purple Mountain is the biography of Chai's grandmother May-En Cao. "Cao is one of the first eight female students of Nanjing Higher Normal School in Chinese modern education history."4 This biography has a lot of highlight in the way of writing: Each of the events in the biography is described separately by Chai and her father. The work shows the different voices of two generations with different life experiences and values. Washington Post Book World once made comments on this book: "In this excellent book, it reveals the conflict between the daughter's urgent desire to know her roots and her father's utmost concealing. As a father, he did not want to reminisce about the past and the changes between himself and his roots." 5 This paper mainly focuses on this book to talk about the narration of women from the Aspect of History in the 20th century in May-Lee Chai's Works.

\section{Chinese History Writing}

May-Lee Chai narrates history from the perspective of women. She prefers the daily history writing to show the turbulence and homeless situation of traditional Chinese women in the long history. On the other hand, she also focuses on women's self-awakening, independence and freedom in the new era. As an outstanding Chinese-American female writer of the 1990s, Chai has a unique perspective to select the narrative objects that shape historical stories. From her grandmother's life to the family and marriage concepts of ordinary career women in new China, she wrote about her characters from her life experience and writing experience. In her main works My Lucky Face and The Girl Form Purple Mountain, she used a large number of words to describe the history and development of China. By reading the text, it can be found that My Lucky Face is a description of Chinese family life during the reform and opening period, which highlights the liberation of women's thought. We can understand the vigorous development of China in the early years of reform and opening period. The Girl Form Purple Mountain describes her grandmother's lifetime with the help of her father's and her own memory. It is more about the turbulence during the Anti-Japanese War, and the strong unyielding spirit of Chinese people in the revolutionary years. The work has a fairly accurate narration of the changes in Chinese society. The work describes the turbulent years during the Anti-Japanese War and during the civil war, as well as the historical features of contemporary China. It is an ideal reading material of Chinese history and culture in the 20th century.

\section{Women who Is the Main Character of the Narration of Human Nature}

Chai is good at describing an era in the perspective of women, expressing the nature attitude of the works through the nature of women. She also corrects the feminine image and the subordinate status of women in western mainstream society by describing ordinary Chinese women. In The Girl Form Purple Mountain written by Chai and her father, she narrates a "heathen" who is the first female student in China and pursues independence by recalling her grandmother's life and past. Women's attention to history or the history of women appeared with the constant development and deepening cognition of women's awareness. In The Girl Form Purple Mountain, Chai set her grandmother as an example to reflect the development of Chinese history and the awareness of female consciousness from the female perspective. There are a few photos of Chai's grandmother in the book. One is a $2 * 3$-inch family photo. Grand-grandfather and grand-grandmother sat in the front pew and the children stood upright. They all wore thick cotton suits. Her grandmother wore a kind of 
Chinese-style garment embroidered with moir. There's also a photo that might be a high school graduation one. Her hair was meticulously tied into a bun, dressed in a nun's black gown with a pendant necklace. There is one more obscure but important photo which is from a copy of a magazine. This is a publicity photo of the eight official female students enrolled by Nanjing Higher Normal University in 1920. Her grandmother, May-En Cao, and seven classmates were pictured with a PE teacher who had just returned from studying modern sports education in the United States. She dressed in a three-quarter sleeved shirt with white collar. She looked stuffy, and a dark blue cotton trousers (a coat skirt) made them look like ducks. This could be the idea of someone who wanted to take a sexy photo. All female geniuses were wearing tracksuits.

Through the description of these three photos, we can see the changes of her grandmother, as a woman in China. The Chinese-style garment embroidered with moir is the simplified women's dress of the Man nationality in late Qing Dynasty. The nun's black gown is the western church costume. The white and black suit is the new fashion in the May 4th Movement period. Through the series of changes in clothing, it can be seen that women have experienced social changes at that time. They gradually stepped out from the family to the society, fought for their right of education, and became the speaker of new ideas and education concepts. The image of May-Lee Chai's grandmother clearly reflects the struggles and liberation of women as part of the history, and also indicates the identity of women as the participants and creators of the historical change.

Comparing with other female writers of Chinese origin on the depiction of female images and the interpretation of human nature, such as Hua Mulan created by Ting-Ting Tang with a male image, or Jiang Wenli described by Amy Tan with a delicate image, Chai writes her characters with her unique gender perspective and historical perspective. She paints a different historical picture with her unique personal experience and subjective feeling. In the oppression of times, her grandmother, May-En Cao, broke the constraint of human nature and became a pathfinder as the protagonist in the narration of history. It is more humanized and better to show their personality charm in the perspective of women. What's more, the historical culture embodied in the female body shows the women's sensibility and softness. Also the female connotation involved in her books is also very rich and diversified.

Through the above description, Chai's novels are extended to the writing of history by the narration of women. For the history part, because she pays attention to the authenticity and objectivity of the history of China, the characters become more attractive, which has gotten rid of the distortion of the description of Chinese traditional women and human nature written by other female writers of Chinese origin. The novel The Girl Form Purple Mountain narrates the independent and optimistic personality of Chai's grandmother with simple words that are based on the history. It highlights the growth of women and the awakening of female consciousness in a plain style during the process of narrating history.

\section{The Gain and Loss in History from the Female Perspective}

\subsection{The Unique Style in Narrating History from Female Perspective.}

As a Chinese-American, although she puts her identity as the starting point, May-Lee Chai doesn't set the American society after immigration as the entry point. Instead of narrating the conflict of identity, cultural construction and family values, She focuses on ordinary Chinese and familiar people, and designs the female voice as the main character in her writing and also the bridge to reflect social unrest. This is the special points in her works. Chai not only defines women from social roles, but also gives women a more important historical mission. The history, which is narrated through women as the center, on one hand, is more abundant, diverse and with humanity colors, so that we can understand the history from a lateral perspective. On the other hand, the way women look at history, their different understandings of the themes of morality, dignity and conscience, always make a sharp contrast between the gain and the loss of history.

"The Girl from Purple Mountain mainly tells the story of the woman, May-En Cao, as the main character in the book, led the family to live through the turbulence period during the Anti-Japanese War and the civil war by her indomitable spirit and tenacious faith. A brave woman, mother, and 
grandmother, always stood at the forefront, leading her family members to avoid political oppression, avoid war, and overcome economic disaster."6 Her grandmother was introduced in detail in the book. In 1920, when the Chinese government just allowed women to go to universities, she was the first batch of women to study in the university. After that, she was invited by the ministry of education of Japan to study in Japan. She was also a devout Christian who could recite the whole bible when she was young. While many Chinese women were still unable to read, she has become an English professor. During the World War II, she acted as Mrs. Mountbatten's interpreter in China. As a brave woman who brought her family to the United States during the war, her family has always believed that she could revitalize her family.

May-Lee Chai completes her portrayal of history with the unique perspective of female writers. The novel, with female consciousness, has an important influence on the reshape of female images and the description of male images. Although there is something unreal in the narration of historical scenes, the unique way that shows the different stages in history opens a new route to constantly explore the female existence in the long time. Chai uses her female writing style to connect the history with the people closely. The ordinary people in history, the history behind ordinary people. Such a narrative angle also shows the other face of history, and it is also an extension of the search for women's history.

The present literary circle has double standards to female writing. On one hand, like male writers, they hope female writers can meet the writing need of mainstream political and culture, serve the society and people's spiritual needs. Besides, they require the females can write with their own style and personality. However, we should know that female writing not only takes the responsibility of representing female culture and history, but also helps females seek for self-development.

\subsection{The Value Pursuit of Female Images.}

The characteristics of the historical description of women in Chai's novels are reflected in the numbers of characters and the repeat times of depictions. It is also reflected in the point that the author has attributes the thinking of many issues to women. The power of women is always the reason to explain the behavior of the characters and promote the expansion of the plots. The female image and the history of women bear the value pursuit of the novel. The writing style of Chai's novels are based on the narration of human nature and history. She has both Chinese and immigrant identities which makes her have the ability to give us a strong feeling of culture impact. This kind of feeling has laid a great foundation for her creation. That is, considering the life experience overseas and human nature, she combines Chinese and foreign literary and artistic ideas to analyze the survival situation of individuals in Chinese history. The literary world that has expanded on this footing has created an irreplaceable picture of modern literature.

A prominent feature of Chai's novels is the writing and shaping of female images. The value proposition that it contains is a kind of pursuit of truth, kindness and beauty. In the book The Girl from Purple Mountain, "My grandmother acted like the wind, and her little round face was shining. She had a lot of work to do and she would do it whenever she has a job. Because she knew god would grace her. When studying in Japan, she rejected many wooers' love because she realized that she still had a lot to do to save the motherland and the nation. After returning to China, she managed a Christian hospital, translated religious literature, and took care of the family and children. She did not do less work than men, and she showed the personal charm and value of women. When women in her age were still binding their feet, she showed the progressive thought. She showed humanity and history with her unique feminine charm."

\section{Conclusion}

From the aspect of human nature, May-Lee Chai takes female as the main character. In the book The Girl from Purple Mountain, she put her grandmother as the representative in the narration. Women's voice is the bridge to reflect the instability and changes of the society. In her works, she ties her ideas toward many questions to women, observes the development of the society and the changes of times from women's eyes. The power of women becomes the reason to explain the characters' 
actions and expand the plots. The image and history of women shows the value pursuit of the novels. That analyzing the unique style of Chai's novels will be a new entry point for studying works of Chinese-American female authors of $\mathrm{X}$ generation.

\section{Acknowledgement}

Fund Project: The youth project of philosophy and social science research program in Heilongjiang the New Voice of Chinese-American Literature - May-Lee Chai's "Chinese Book"(16WWC01) Periodic results.

\section{References}

[1] Yong-Hua Mu. The Construction of Chinese Female Images from the Perspective of Western Culture - Interpreting My Lucky Face [J]. Journal of Taiyuan Urban Vocational College, 2010(07).

[2] http://www.wansongpu.com/bbs/dispbbs.asp?BoardID=5\&id=53413\&replyID=317731\&skin=0

[3] May-Lee Chai and Winberg Chai. The Girl from Purple Mountain [M]. New York: ST. Martin's Griffin, 2002.

[4] Wen-Shu Zhao. A Review of Non-fictional Works of American Chinese Literature in the Past Century [J]. Journal of Jiangsu Teachers University of Technology, 2006(02).

[5] Yong-Hua Mu, Ying Li. The Supported the History of Nanjing University by the American Novel the Girl from Purple Mountain [N]. Journal of Nanjing University-Students' Life, 2006(10). 